\title{
Pathogens Contamination Level Reduction on Beef Using Organic Acids Decontamination Methods
}

\author{
Sorin Daniel DAN ${ }^{* 1}$, Marian MIHAIU ${ }^{1}$, Oana REGET ${ }^{1}$, Delia OLTEAN $^{2}$ and Alexandra TĂBĂRAN ${ }^{1}$ \\ ${ }^{1}$ Department of Animal Production and Food Safety, Faculty of Veterinary Medicine, University of \\ Agricultural Sciences and Veterinary Medicine, Cluj-Napoca, Romania \\ ${ }^{2}$ Sanitary Veterinary and Food safety laboratory Alba County, Department of Food Microbiology, Alba \\ Iulia, 7 A Lalelelor Street, Alba County \\ *corresponding author: sorindan@usamvcluj.ro
}

Bulletin UASVM Veterinary Medicine 74(2)/2017

Print ISSN 1843-5270; Electronic ISSN 1843-5378

doi:10.15835/buasvmen-vm:0052

\begin{abstract}
In this study we aimed to assess the efficiency of organic acids in different concentrations regarding pathogens as Salmonella, Listeria and Escherichia on beef, which can cause food borne illness in humans. The samples were sterilized using UV radiation for 30 minutes, afterwards being contaminated with $1 \mathrm{ml}$ of microbial suspension (0.5 MacFarland). We used reference bacterial strains for Salmonella Enteritidis, Escherichia coli and Listeria monocytogenes. The samples were subjected to decontamination procedure by introducing $25 \mathrm{~mL}$ of solution of lactic, acetic or citric acid in concentration of $1 \%, 2 \%$ and 3\%. The results showed a reduction of initial pathogen load, ranging from 0.32 to $7.78 \mathrm{log} \mathrm{CFU} / \mathrm{g}$, depending on the type of acid, concentration and pathogen sensitivity. After decontamination, standardized methods have been used for the isolation of pathogenic germs. Based on statistical analysis we conclude that pathogens have a different sensitivity to the action of acid solutions, their sensitivity in ascending order being: Listeria monocytogenes, Salmonella Enteritidis and Escherichia coli. Among the organic acids, the most efficient was lactic acid, followed by acetic acid and less efficient citric acid. The greatest reduction of germs was determined by the concentration of $3 \%$.
\end{abstract}

Keywords: pathogens, decontamination methods, bovine carcasses

\section{INTRODUCTION}

Bovine carcasses can become contaminated with pathogens bacteria during slaughtering process, mainly due to lack of Good Hygiene Practices (GHP) and Good Manufacturing Practices (GMP) in the hiding and evisceration steps (Smulders and Greer, 1998; Sofos, 2008; Loretz et al., 2011). Pathogenic microorganisms, once in the body through food consumption, can cause food poisoning especially in developing countries, affecting a large number of consumers (Boslaugh, 2008). For these reasons, the competentauthorities of each country has an interest in adopting appropriate prevention measures to reduce the prevalence of food-borne illnesses. Numerous studies have demonstrated the effectiveness of using decontamination methods in order to reduce the level of pathogens, among which the most commonly used are: organic acids (lactic acid, citric acid, acetic acid), alkaline solutions (trisodium phosphate), steam, chlorinated water or ozone (Dorsa et al., 1998; Smulders and Greer, 1998; Castillo et al., 1999; Gonzales and Domongoz, 2006; Carpenter et al, 2011, Loretz et al., 2011). Depending on the concentration of the chemical solutions used, the reduction of pathogen load was variable, ranging from $0.4 \log \mathrm{CFU} / \mathrm{cm}^{2}-4.5 \mathrm{log}$ $\mathrm{CFU} / \mathrm{cm}^{2}$ (Ramson et al., 2003; Sohaib et al., 2016). Based on EFSA's scientific opinion, in accordance with current legislation, only lactic acid solutions in bovine carcasses can be used in the EU, with the indication that it is introduced in the HACCP plan 
(EFSA, 2011; Reg CE 101/2013). Therefore, the aim of this study was to evaluate the effectiveness of different organic acid solutions regarding pathogenic microorganisms from Salmonella, Escherichia and Listeria genera from bovine meat.

\section{MATERIALS AND METHODS}

Sixteen samples of chilled meat from a bovine slaughterhouse located in Alba County were collected between November 2016 and April 2017. The samples were packed in sterile polyethylene foil, placed in isothermal bags at 4 $6^{\circ} \mathrm{C}$ and transported to the Sanitary Veterinary and Food Safety Laboratory Alba County, within the department of Food microbiology, where they were processed. In order to achieve the aforementioned objectives, the following reference strains for pathogenic germs were used: Salmonella Enteritidis ATCC 13076 (Microbiologics, USA), Escherichia coli ATCC 25922 (Microbiologics, USA), Listeria monocytogenes ATCC 19114 (Microbiologics, USA). For the contamination of samples with the above-mentioned pathogenic germs, the lyophilized cultures were suspended in a nutrient broth maintained at $37^{\circ} \mathrm{C}$ for 24 hours in Salmonella spp. and E. coli and TSYEB maintained for 48 hours in case of Listeria monocytogenes. After incubation, inoculation was performed on specific selective specific media (XLD-Salmonella spp., TBX - E. coli, ALOA - Listeria monocytogenes), which were thermostated at $37^{\circ} \mathrm{C}$ for $24-48$ hours. For each type of pathogen germ, 5 specific colonies were subjected to cultural and morphological confirmation tests. From the selective media, the colonies were cultured on nutrient agar, which was incubated at $37^{\circ} \mathrm{C}$ for 24 hours. Afterwords, biochemical and serological tests were performed to confirm that the isolated strains were pure. In order to obtain microbial suspensions with a specific number of bacteria, colonies developed on the nutrient agar were homogenized in 5 $\mathrm{ml}$ sterile saline solutions in test tubes until a turbidity of 0.5 on the MacFarland scale was obtained, verified with the Densimat apparatus (Biomerieux). According to the manufacturer's stipulations, the value of 0.5 corresponds to a load of microorganisms of $150 \times 10^{6} \mathrm{CFU} / \mathrm{ml}$. The collected samples were sterilized inside the microbiological cabinet using UV radiation for 30 minutes in order to inactivate any pathogenic germs. Three solutions of organic acids: lactic, acetic and citric in different concentrations (1\%, $2 \%$ and $3 \%$ respectively) were used to assess the antimicrobial potential.

In order to evaluate the decontamination effect of some organic acid solutions, the samples were processed as follows: each beef sample was divided into 11 sub-samples of $25 \mathrm{~g}$, from which one was the negative control (un-contaminated). 9 samples have undergone the decontamination process with the aforementioned organic acid solutions, and the latter has been a positive control (non-decontaminated). Samples 2-10 (25 $\mathrm{g}$ of meat each) were contaminated with $1 \mathrm{ml}$ of microbial suspension ( 0.5 MacFarland), then homogenized for 30 seconds in the Stomacher device (230 rpm), leaving 30 minutes at $20^{\circ} \mathrm{C}$ to ensure the adhesion of bacteria to muscle tissue. Afterword's, samples 2-10 were subjected to the decontamination procedure by adding 25 $\mathrm{ml}$ of $1 \%, 2 \%$ and $3 \%$ citric acid solution, acetic acid and citric acid respectively, followed by homogenization in Stomacher $(230 \mathrm{rpm}$, for 30 seconds), being maintained for 1 minute at $20^{\circ}$ $\mathrm{C}$ for the decontamination effect. For isolation of Salmonella, Escherichia and Listeria strains, 225 $\mathrm{ml}$ of buffered peptone water (APT), semi-Fraser broth and Bolton broth were added to samples $1-11$, performing serial dilutions: $10^{-2}, 10^{-3}, 10^{-4}$, $10^{-5}, 10^{-6}, 10^{-7}, 10^{-8}$. For the isolation of pathogenic germs standardized methods have been used, according to the current legislation (SR EN ISO 6579 AC/2009, SR EN ISO 11290-1/A1/2005, and SR EN ISO 16649-2/2007). Statistical analysis of the results was carried out using Origin 8.5 software program by comparison of means by analysis of variance through ANOVA test.

\section{RESULTS AND DISCUSSIONS The decontamination effect of organic acid solutions on Salmonella Enteritidis}

Based on the results, it was found that $1 \%$ acetic acid solution showed a reduction of Salmonella Enteritidis from 6.78 to $5.64 \pm 0.16$ $\log$ CFU/g (1.14 log reduction), of $5.38 \pm 0.11 \log$ $\mathrm{CFU} / \mathrm{g}$ in case of the lactic acid solution $1 \%(1.4$ $\log$ reduction), and of $5.96 \pm 0.07 \mathrm{log} \mathrm{CFU} / \mathrm{g}(0.90$ $\log$ reduction) in case of citric acid 1\% (Figure 1). After application of $2 \%$ organic acids solutions, the Salmonella load decreased at $4.56 \pm 0.04 \mathrm{log}$ $\mathrm{CFU} / \mathrm{g}$ for acetic acid (2.22 log reduction), to 4.54 $\pm 0.07 \log \log \mathrm{CFU} / \mathrm{g}$ for lactic acid, respectively (of 


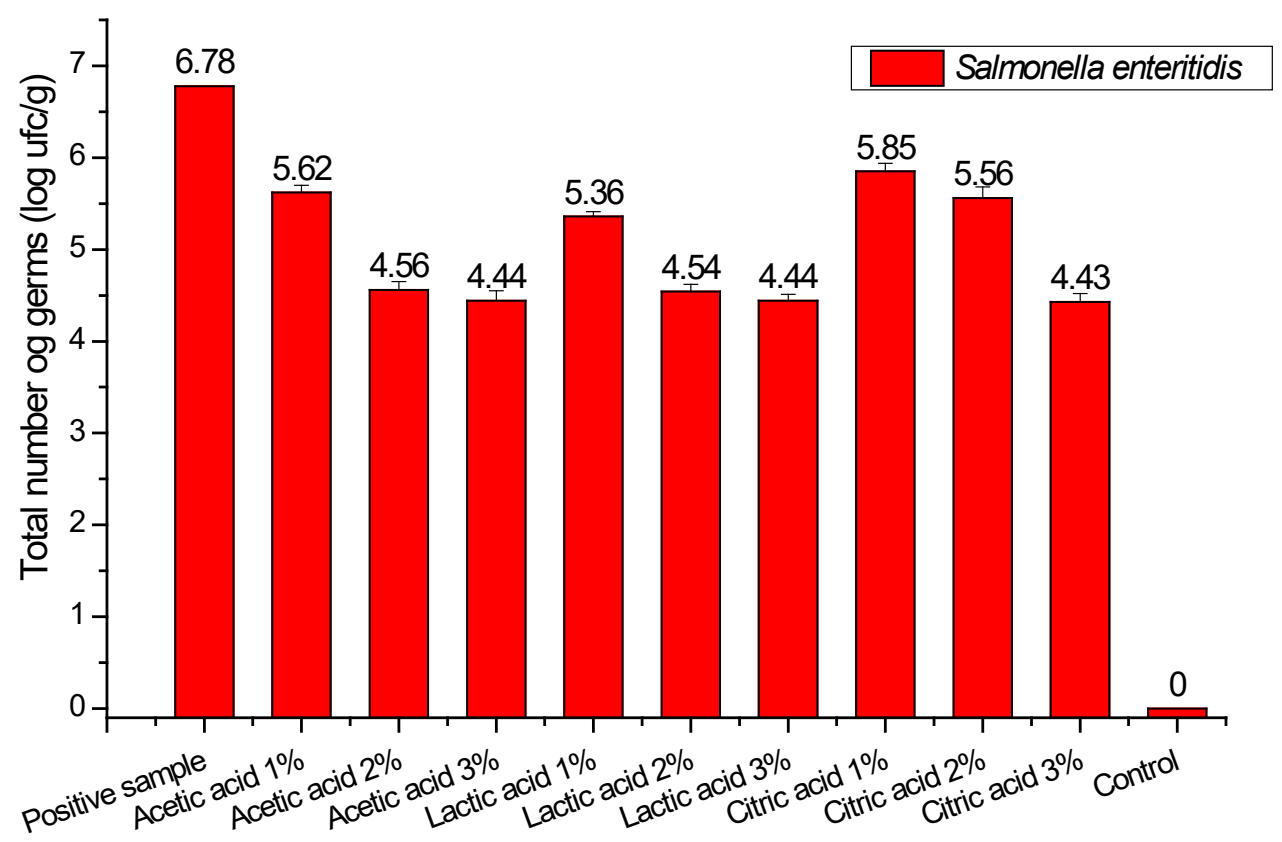

Fig.1. Decontamination effect of $1 \%, 2 \%$ and $3 \%$ of acetic, lactic and citric acid regarding Salmonella Enteritidis on beef samples $(n=3)$

$2.24 \log$ reduction), and $5.56 \pm 0.09 \log \mathrm{CFU} / \mathrm{g}$ for citric acid (1.22 log reduction) (Fig. 1).

A significant reduction was noticed in case of using organic acids in concentrations of $3 \%$. Thus, the Salmonella load was reduced to $4.44 \mathrm{log}$ $\mathrm{CFU} / \mathrm{g}$ after using acetic and lactic acid (2.34 log reduction) and in the case of citric acid the load decreased to $4.43 \log \mathrm{CFU} / \mathrm{g}$ (2.35 log reduction) (Figure 1). Statistical analyzes revealed significant differences regarding Salmonella Enteritidis load between positive samples (contaminated) and decontaminated samples with organic acid solutions ( $\mathrm{p}<0.05)$, and no differences were recorded between the same concentration of organic acid solutions.

Results similar to those obtained by us were published by Castillo et al. (2001), in a study on the efficacy of Salmonella Enteritidis reduction methods from the surface of chilled cattle carcasses, which showed a reduction between 1.6-1.9 log when using 2\% lactic acid. Similarly, Harris et al. (2006) showed a reduction of E. coli and Salmonella spp. between 1.5 and $2.0 \mathrm{log}$, in the case of lactic acid concentration of $2 \%$ and $4 \%$, respectively.
The decontamination effect of organic acid solutions on E. coli

Following application of the $1 \%$ acetic acid solution, the initial load of Escherichia coli decreased to $6.72 \pm 0.08 \mathrm{log} \mathrm{CFU} / \mathrm{g}$ (0.06 log reduction), to $6.56 \log \pm 0.10 \mathrm{CFU} / \mathrm{g}$ after lactic acid use (0.12 log reduction) and $6.56 \pm 0.16 \log$ $\mathrm{CFU} / \mathrm{g}$ after utilization of citric acid (0.12 log reduction).

Following the use of $2 \%$ organic acid solutions the initial load of E. coli decreased to $6.46 \pm 0.06$ $\log \mathrm{CFU} / \mathrm{g}(0.32 \mathrm{log}$ reduction) in case of acetic acid, $6.37 \pm 0.04 \log$ CFU/g for lactic acid and 6.38 $\pm 0.04 \log \mathrm{CFU} / \mathrm{g}$ for citric acid (Figure 2), with a reduction of $0.40 \log$. A more significant decrease was recorded in case of the use of $3 \%$ organic acids solutions. Thus, after the application of acetic acid, a decrease to $5.56 \pm 0.13 \log$ CFU/g (1.22 log reduction), to $5.45 \pm 0.08 \log \mathrm{CFU} / \mathrm{g}$ for lactic acid (1.33 log reduction) and to $5.85 \pm 0.08 \log \mathrm{CFU} / \mathrm{g}$ for citric acid (Figure 2). Significant differences were recorded only in case of $2 \%$ and $3 \%$ acetic and lactic acid solutions ( $p<0.05)$ in comparison with the control sample regarding the effect of on the total load of Escherichia coli. Regarding the efficiency of lactic acid solutions $(1 \%, 2 \%, 3 \%)$ in comparison with acetic acid solutions $(1 \%, 2 \%$, 


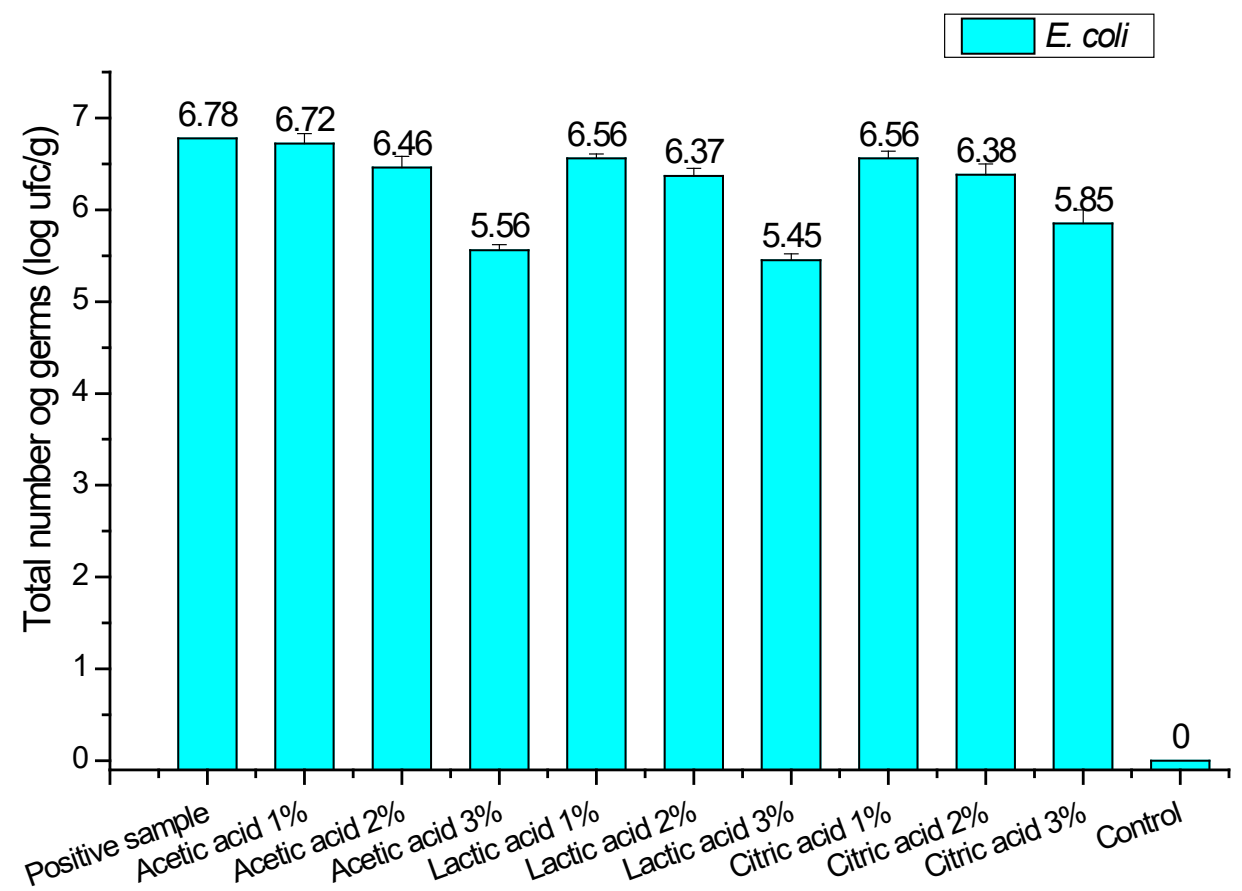

Fig.2. Decontamination effect of $1 \%, 2 \%$ and $3 \%$ of acetic, lactic and citric acid regarding $E$. coli on beef samples (n=3)E

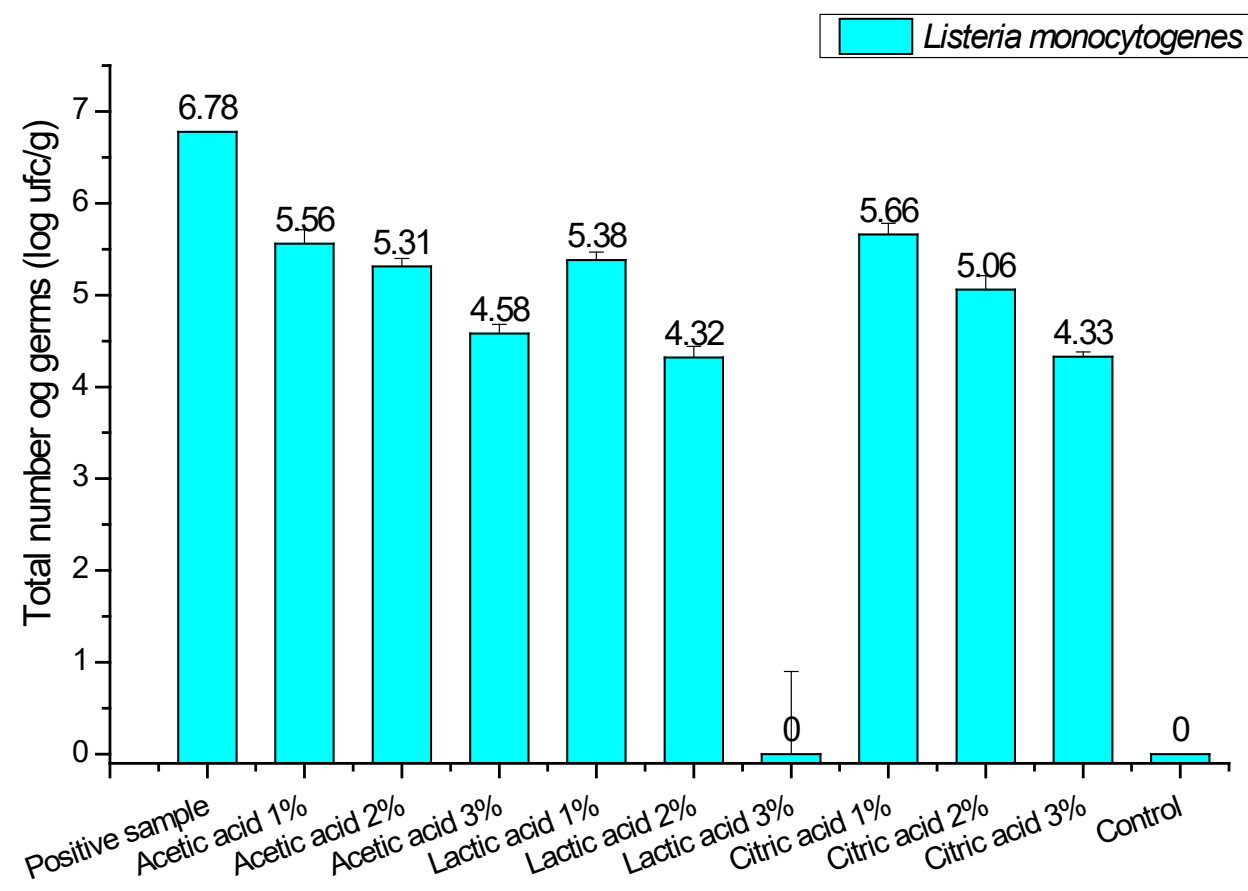

Fig.3. Decontamination effect of $1 \%, 2 \%$ and $3 \%$ of acetic, lactic and citric acid regarding Listeria monocytogenes on beef samples $(n=3)$ 
$3 \%$, significant differences were found only in case of $1 \%$ concentration $(\mathrm{p}<0.05)$.

A study by Castilo et al. (2001) on the efficiency of $E$. coli reduction methods on chilled bovine carcass surfaces revealed a more pronounced reduction compared to those obtained in our study, ranging from 2.0-2.4 log when using 2\% lactic acid. Similar results have been mentioned by Delazari et al. (1998), who found lower values than $0.3 \log \mathrm{CFU} / \mathrm{cm}^{2}$ when used $1.5 \%$ acetic acid to the contaminated carcasses. Different results regarding acetic acid solutions were reported by Gorman et al. (1995), who reported an E. coli reduction of $2.0 \log \mathrm{cm}^{2}$ when using acetic acid $2 \%$. Similarly, Algino et al. (2007) reported a reduction in E. coli of $0.71 \log \mathrm{CFU} / \mathrm{cm}^{2}$ and $0.81 \mathrm{CFU} / \mathrm{cm}^{2}$ after application of $2.5 \%$ acetic acid.

The decontamination effect of organic acid solutions on Listeria monocytogenes

The results regarding $L$. monocytogenes showed a decrease of initial microbial load after application of $1 \%$ organic acid solutions, as follows: in case of acetic acid, the level of microorganisms decreased to $5.56 \pm 0.11 \log$ $\mathrm{CFU} / \mathrm{g}$ (1.22 log reduction), to $5.38 \pm 0.06 \mathrm{log}$ $\mathrm{CFU} / \mathrm{g}$ (1.40 log reduction) for lactic acid and 5.66 $\pm 0.08 \log \mathrm{CFU} / \mathrm{g}$ for citric acid, with a decrease of $1.12 \log$ (Figure 3). A more pronounced decrease in microbial load was recorded in case of using of $2 \%$ organic acids solutions, since from the initial load of $6.78 \mathrm{log} \mathrm{CFU} / \mathrm{g}$, it reached $5.31 \pm 0.18 \mathrm{log}$ $\mathrm{CFU} / \mathrm{g}$ using acetic acid (reduction of $1.47 \mathrm{log}$ ), $4.32 \pm 0.14 \log \mathrm{CFU} / \mathrm{g}$ for lactic acid (reduction of 2.46 ) and $5.06 \pm 0.16 \mathrm{log} \mathrm{CFU} / \mathrm{g}$ in case of citric acid (reduction of 1.72) (Figure 3). The greatest reduction of microbial load was recorded in the use after application of 3\% lactic acid solution, which determined a complete inactivation of Listeria monocytogenes. In the case of acetic acid the load of Listeria monocytogenes was reduced to $4.58 \pm 0.06 \log \mathrm{CFU} / \mathrm{g}$ (3.20 log reduction) and $4.33 \pm 0.30 \log \mathrm{CFU} / \mathrm{g}$ for citric acid (3.45 log reduction) (Figure 3 ).

Statistical analysis found significant differences regarding the effect of acetic acid in comparison with lactic acid solutions in regard with the total load of Listeria monocytogenes compared to the control sample for the three concentrations used ( $p$ <0.05). From the comparative analysis of the efficacy of lactic acid solutions $(1 \%, 2 \%$, $3 \%$ ) compared to those treated with acetic acid
(1\%, 2\%, 3\%), significant differences were found only in case of $2 \%$, respectively $3 \%$ organic acid solution $(\mathrm{p}<0.05)$.

\section{CONCLUSION}

Based on our results we conclude that the pathogens have a different sensitivity to the action of the decontaminating acid solutions, their sensitivity in ascending order being the following: Escherichia, Salmonella and Listeria, 3\% lactic acid solution caused total inhibition of Listeria monocytogenes; the effectiveness of solutions of organic acids in descending order was: lactic acid, acetic acid and citric acid. These methods of decontamination should be considered as complementary measures to increase the safety of meat, in addition to GMP and GHP.

\section{REFERENCES}

1. Algino RJ, Ingham SC, Zhu J (2007). Survey of antimicrobial effects of beef carcass intervention treatments in very small state-inspected slaughter plants. Journal of Food Science, 72: 173-179.

2. Bacon RT (2000). Comparison of three commercial beef carcass decontamination systems. The Department of Animal Sciences Colorado State University, 2000. Research Report

3. Carpenter CE, Smith JV, Broadbent JR (2011). Efficacy of washing meat surfaces with $2 \%$ levulinic, acetic, or lactic acid for pathogen decontamination and residual growth inhibition. Meat Science, 88: 256-260.

4. Castillo A, Lucia LM, Roberson DB, Stevenson TH, Mercado I, Acuff JR (2001). Lactic acid sprays reduce bacterial pathogens on cold beef carcass surfaces and in subsequently produced ground beef, J Food Prot., 64(1): 58-62.

5. Castillo A, Lucia LM, Goodson KJ, Savell JW, GR (1999). Decontamination of beef carcass surface tissue by steam vacuuming alone and combined with hot water and lactic acid sprays. Journal of Food Protection, 61: 823-828.

6. Delazari I, Iaria ST, Riemannm HT, Cliver DO, Mori $\mathrm{T}$ (1998). Decontaminating beef for Escherichia coli 0157:H7. Journal of Food Protection, 61: 547-550.

7. Dorsa WJ, Cutter CN, Siragusa GR (1998). Long-term effect of alkaline, organic acid or hot water washes on the microbial profile of refrigerated beef contaminated with bacterial pathogens after washing. Journal of Food Protection, 61: 300-306.

8. Gorman BM, Sofos JS, Morgan JB, Schmidt GR, Smith GC (1995). Evaluation of hand-trimming, various sanitizing agents, and hot water spray washing as decontamination interventions for beef brisket adipose tissue. Journal of Food Protection, 58: 899-907.

9. Harris K, Miller MF, Loneragan GH, Brashears MM (2006) Validation of the use of organic acids and acidified sodium chlorite to reduce Escherichia coli 0157 and Salmonella 
typhimurium in beef trim and ground beef in a simulated processing environment. J. Food Prot., 69:1802-1807.

10. Loretz M, Stephan R, Zweifel C (2008). Antibacterial activity of decontamination treatments for cattle hides and beef carcasses. Meat Science, 88: 256-260.

11. Ransom JR, Belk KE, Sofos JN, Stopforth JD, Scanga jA, Smith GC (2003). Comparison of intervention technologies for reducing Escherichia coli 0157:H7 on beef cuts and trimmings. Food Protection Trends, 23: 24-34.

12. Smulders FJ, Greer GC (1998). Integrating microbial decontamination with organic acids in HACCP programs for muscle foods: prospects and controversies. International Journal of Food Microbiology, 44: 149-169.
13. Sofos JN (2008). Challenges to meat safety in the 21st century. Meat Science, 78: 3-13.

14. ${ }^{* * *}$ Reg. (EU) 101/2013 of 4 February 2013 concerning the use of lactic acid to reduce microbiological surface contamination on bovine carcasses.

15. *** SR EN ISO 6579/2003, SR EN ISO 6579 AC/2009, Metoda orizontală pentru detectarea bacteriilor din genul Salmonella.

16. *** SR EN ISO 11290-1/2000, SR EN ISO 11290-1/A1 2005, Metoda orizontală pentru detectarea şi numărarea Listeria monocytogenes.

17. *** SR EN ISO 16649-2/2007, Metoda orizontală pentru numărarea Escherichia coli pozitivă la $\beta$-glucuronidază. 